\title{
EHMTI-0387. Characterization of peripheral and central sensitization in patients undergoing occipital nerve stimulator implant for intractable migraine
}

\author{
V Mehta $^{1 *}$, A Bahra $^{2}$, L Casey $^{1}$, A Alamgir ${ }^{1}$, R VanGroningen $^{3}$, T Wodehouse $^{1}$ \\ From 4th European Headache and Migraine Trust International Congress: EHMTIC 2014 \\ Copenhagen, Denmark. 18-21 September 2014
}

\section{Introduction}

Trigemino-spinal sensitization and impaired descending inhibitory control (DNIC) has been reported in chronic migraine.1 Further mechanism behind occipital nerve stimulation (ONS) remains speculative.

\section{Aims}

This observational study characterises peripheral and central sensitization in patients undergoing ONS for intractable chronic migraine

\section{Methods}

Quantitative Sensory testing (QST) measurements were carried out in patients before and after ONS $(n=6)$.

1. Measurement of pressure pain thresholds (PPT): Computer-controlled pressure algometer (SomedicAB, Sweden, diameter contact tip $10 \mathrm{~mm}$; standardised speed $0.3 \mathrm{~kg} / \mathrm{s}$ ) measured PPTs at standardized three points (temple, cheek bone and cervical).

2. DNIC: DNIC response was measured using PPT on cheekbone with an inflated cuff insitu on one arm.

\section{Results}

Patients with chronic migraine demonstrated loss of DNIC, (PPTs $56.0 \mathrm{KPa}$ vs $46.2 \mathrm{kPA}$ cuff inflated). A "normal' DNIC response was observed two weeks following ONS (58.4 kPA vs $100.4 \mathrm{kPA}$ cuff inflated) continuing positively over next three months. In contrast the PPTs remained same before and after the ONS.

'Pain \& Anesthesia Research Centre St Bartholomew's Hospital, Bart's Health NHS Trust, London, UK

Full list of author information is available at the end of the article

\section{Conclusion}

This case series reports sustained reversal of the loss of DNIC response in patients undergoing ONS for intractable headache whilst having no effect on peripheral pain thresholds.

No conflict of interest.

\section{Authors' details}

'Pain \& Anesthesia Research Centre St Bartholomew's Hospital, Bart's Health NHS Trust, London, UK. ${ }^{2}$ Department of Neurology Whipps Cross Hospital, Bart's Health NHS Trust, London, UK. ${ }^{3}$ Department of Neurosurgery Royal London Hospital, Bart's Health NHS Trust, London, UK.

Published: 18 September 2014

\section{Reference}

1. Boyer N: Pain 2014, 155:1196-205.

doi:10.1186/1129-2377-15-S1-M8

Cite this article as: Mehta et al:: EHMTI-0387. Characterization of peripheral and central sensitization in patients undergoing occipital nerve stimulator implant for intractable migraine. The Journal of Headache and Pain 2014 15(Suppl 1):M8.

\section{SpringerOpen ${ }^{\odot}$}

(C) 2014 Mehta et al; licensee Springer. This is an Open Access article distributed under the terms of the Creative Commons Attribution License (http://creativecommons.org/licenses/by/2.0), which permits unrestricted use, distribution, and reproduction in any medium, provided the original work is properly cited.
Submit your manuscript to a SpringerOpen ${ }^{\circ}$ journal and benefit from:

- Convenient online submission

- Rigorous peer review

- Immediate publication on acceptance

- Open access: articles freely available online

- High visibility within the field

Retaining the copyright to your article

Submit your next manuscript at $>$ springeropen.com 